\title{
Inflammatory cytokine regulation of TRAIL-mediated apoptosis in thyroid epithelial cells
}

\author{
JD Bretz ${ }^{2,5}$, E Mezosi ${ }^{2,5}$, TJ Giordano ${ }^{3}$, PG Gauger ${ }^{4}$, \\ NW Thompson ${ }^{4}$ and JR Baker, Jr ${ }^{\star, 1,2}$ \\ ${ }^{1}$ Center for Biologic Nanotechnology, University of Michigan Medical Center, \\ Ann Arbor, Michigan, USA \\ 2 Department of Medicine, University of Michigan Medical Center, Ann Arbor, \\ Michigan, USA \\ ${ }^{3}$ Department of Pathology, University of Michigan Medical Center, Ann Arbor, \\ Michigan, USA \\ ${ }^{4}$ Department of Surgery, University of Michigan Medical Center, Ann Arbor, \\ Michigan, USA \\ 5 The first two authors contributed equally to this manuscript \\ * Corresponding author: JR Baker, Jr, University of Michigan Medical Center, \\ 9220 MSRB III, Ann Arbor, MI 48109-0648, USA. Tel: (734) 647-2777; \\ Fax (734) 936-2990; E-mail: jbakerj@@umich.edu
}

Received 27.4.01; revised 30.8.01; accepted 27.9.01 Edited by CJ Thiele

\begin{abstract}
Death receptor-mediated apoptosis has been implicated in target organ destruction in chronic autoimmune thyroiditis. Depending on the circumstances, inflammatory cytokines such as IL-1, TNF and IFN $\gamma$ have been shown to contribute to either the induction, progression or inhibition of this disease. Here we demonstrate that the death ligand TRAIL can induce apoptosis in primary, normal, thyroid epithelial cells under physiologically relevant conditions, specifically, treatment with the combination of inflammatory cytokines IL-1 $\beta$ andTNF $\alpha$. In contrast, IFN $\gamma$ is capable of blocking TRAIL-induced apoptosis in these cells. This regulation of TRAIL-mediated apoptosis by inflammatory cytokines appears to be due to alterations of cell surface expression of TRAIL receptor DR5 and not DR4. We also show the in vivo presence of TRAIL and TRAIL receptors DR5 and DcR1 in both normal and inflamed thyroids. Our data suggests TRAIL-mediated apoptosis may contribute to target organ destruction in chronic autoimmune thyroiditis.

Cell Death and Differentiation (2002) 9, 274-286. DOI: 10.1038/ $\mathrm{sj} / \mathrm{cdd} / 4400965$
\end{abstract}

Keywords: apoptosis; autoimmune disease; death receptor 5; decoy receptor; inflammatory cytokine; interferon gamma

Abbreviations: $\mathrm{Ab}$, antibody; $\mathrm{CHX}$, cycloheximide; $\mathrm{CK}$, cytokeratin; DcR, decoy receptor; DR, death receptor; FITC, fluorescein isothiocyanate; GAPDH, glyceraldehyde-3 phosphate dehydrogenase; IFN, interferon; IL, interleukin; PBS, phosphate-buffered saline; TEC, thyroid epithelial cell; TNF, tumor necrosis factor; TRAIL, TNF-related apoptosis-inducing ligand

\section{Introduction}

Apoptosis is a normal, active, genetically controlled process of cell death that does not require the participation of the inflammatory process. ${ }^{1}$ Apoptosis mediates several normal functions in human biology including elimination of unneeded or unwanted cells in development, organ homeostasis, and immune regulation and defense. ${ }^{2-4} \mathrm{~A}$ primary pathogenic event in the development of autoimmune endocrine diseases is the immune-mediated destruction of a particular type of endocrine cell. Clinical disease in chronic autoimmune thyroiditis is caused by the specific cytotoxic destruction of thyroid follicular cells through apoptosis. This is a similar process to what appears to cause clinical illness in type I diabetes, where cytotoxic destruction of islet $\beta$ cells leads to inadequate insulin production and hyperglycemia. ${ }^{6}$ Immunemediated apoptosis, specifically triggered through the death receptor Fas, is believed to be central to the pathogenesis of autoimmune diabetes because apoptosis destroys islet $\beta$ cells in both animal models of diabetes and the human type I disease $^{7,8}$ and animals that do not express normal Fas do not develop disease. ${ }^{9}$ Recent evidence suggests that this is due to loss of target cell susceptibility to apoptosis rather than disruption of the immune response by alteration of Fas. ${ }^{10}$ Fasmediated destruction has also been proposed as the cause of hypothyroidism in chronic autoimmune thyroiditis. ${ }^{11-14}$ Other death receptors (DR), such as DR4 (TRAIL-R1) and DR5 (TRAIL-R2, TRICK2, KILLER), may also be involved in this process, but due to their very recent characterization have not been evaluated. Thus, apoptosis signaled through the Fas or other death receptor pathways might also be important in the pathogenesis of thyroid disease.

Activated T lymphocytes expressing death ligands such as FasL and TRAIL (the ligand for DR4 and DR5 as well as decoy receptors DcR1 [TRAIL-R3, TRID, LIT], DcR2 [TRAIL$\mathrm{R} 4, \mathrm{TRUNDD}$ ] and osteoprotogerin) may be responsible for inducing thyroid cell destruction during the inflammatory response to thyroid autoantigens. In fact apoptotic thyroid follicular cells are often found in close proximity to infiltrating lymphocytes in inflamed thyroids. ${ }^{15,16}$

Inflammatory cytokines are present in inflamed thyroids and have been shown to influence thyroid disease in experimental autoimmune thyroiditis animal models. ${ }^{17}$ Direct experimental evidence for the involvement of inflammatory cytokines IFN $\gamma$, TNF $\alpha$ and IL-1 $\beta$ in experimental autoimmune thyroiditis has been well-documented. ${ }^{18-23}$ Regulation of death receptor pathways in the thyroid may be a potential mechanism in which inflammatory cytokines might act to promote disease progression. Several groups, including our own, have shown the influence of inflammatory cytokines in Fas-mediated apoptosis of cultured thyroid cells ${ }^{11,12,24,25}$ and reviewed in Borgerson et al. ${ }^{14}$ We have also shown that thyroid epithelial cells (TECs) are susceptible to TRAIL-mediated apoptosis 
after pretreatment with cycloheximide $(\mathrm{CHX})$ and that TRAIL itself is expressed by the TECs treated with IFN $\gamma$, TNF $\alpha$ or IL$1 \beta .^{26}$ Combined, this data suggests that TRAIL-mediated apoptosis may have a role in autoimmune thyroiditis.

We have identified physiologically relevant conditions in which TRAIL can mediate apoptosis in normal primary TECs. In this study we demonstrate that pretreatment of thyroid cells with the combination of $\mathrm{TNF} \alpha$ and $\mathrm{IL}-1 \beta$ provides a signal that allows for TRAIL-mediated apoptosis. The apoptotic activity appears to be mediated by the movement of DR5 from the cytoplasm to the cell surface where it can transmit the death signal. Conversely, DcR1 is removed from the cell surface under these conditions. In contrast, IFN $\gamma$ protects against cell death through this pathway by preventing DR5 movement to the cell surface. We also show the in vivo presence of TRAIL and its receptors DR5 and DcR1 in chronic autoimmune thyroiditis. Combined, this data further suggests a role for the TRAIL death pathway in autoimmune thyroiditis. These findings may also be important to the current debate regarding the potential use of TRAIL as an anti-cancer agent as they suggest TRAIL treatment may accelerate destruction of inflamed thyroid tissue and that IFN $\gamma$ may have a protective role in this process.

\section{Results}

\section{TNF $\alpha$ combined with IL- $\beta$ induces susceptibility to TRAIL-mediated apoptosis in thyroid cells}

We have previously demonstrated that both FasL and TRAIL are capable of inducing apoptosis in TECs after $\mathrm{CHX}$
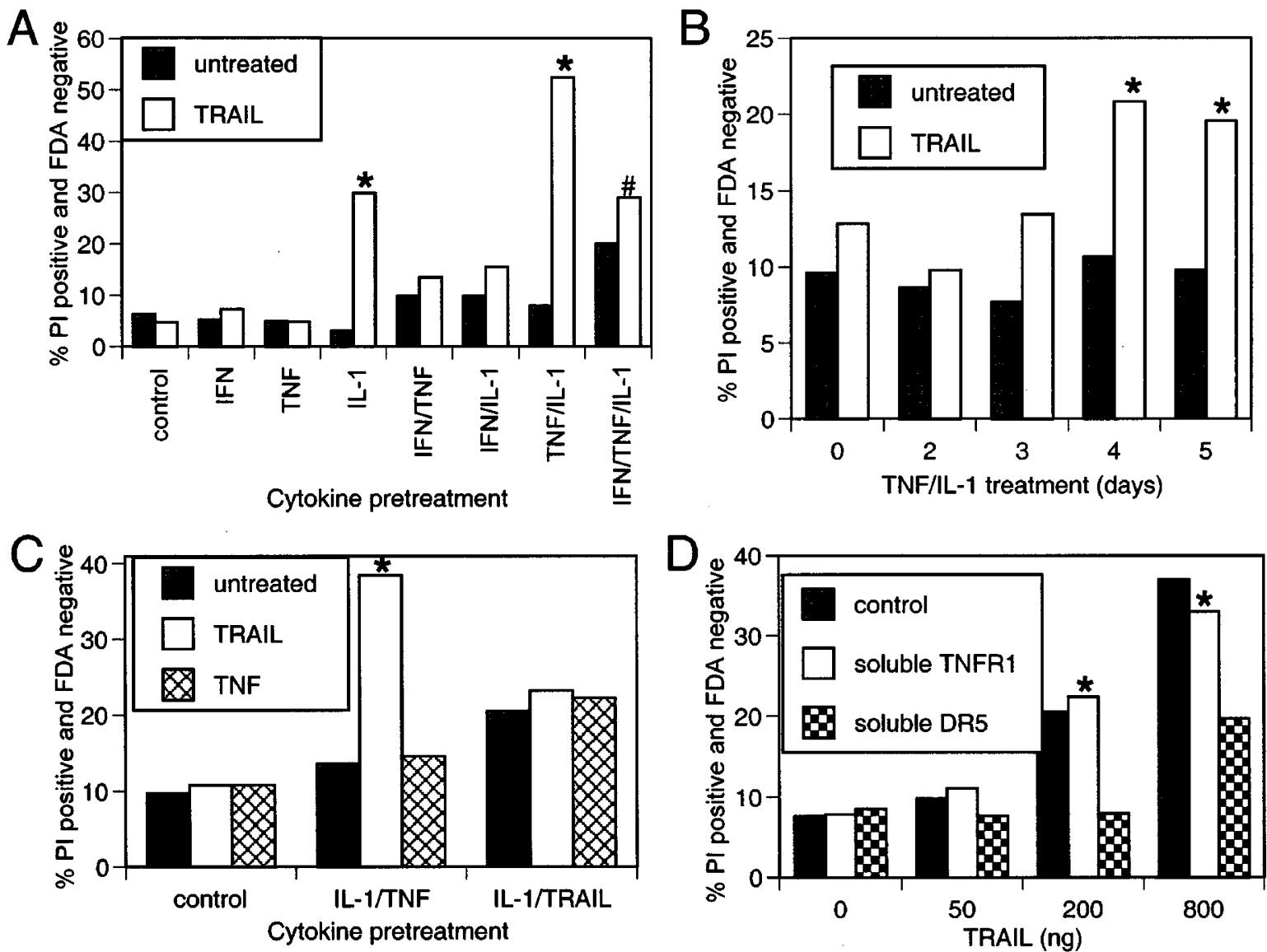

Figure 1 Inflammatory cytokines induce susceptibility to TRAIL-mediated cell death in TECs. (A) Normal primary TEC cultures were pretreated for 4 days with the indicated cytokines prior to addition of TRAIL $(800 \mathrm{ng} / \mathrm{ml})$. Cells were harvested after $18 \mathrm{~h}$ by combining non-adherent cells in the culture media with trypsinized adherent cells, washed in PBS and stained with PI and FDA for quantitation by flow cytometry. 10000 cells/sample were assayed for live and dead cells. Asterisks denote results of TRAIL treatment with $P<0.0001$ (chi-squared test) when compared separately with both the control sample (no cytokines) and untreated (cytokines but no TRAIL). The \# symbol denotes the result of TRAIL treatment with $P<0.0001$ (chi-squared test) when compared with TNF/IL-1/TRAIL treatment. This assay is representative of results from 10 independent experiments each using thyroid cultures from different patient samples. (B) Cultures were treated and assayed as above except cytokines were added to cultures for the indicated number of days prior to the addition of TRAIL and cells were harvested after $6 \mathrm{~h}$ incubation with TRAIL. Asterisks denote results of TRAIL treatment with $P<0.0001$ (chi-squared test) when compared separately with both the control sample (day 0 ) and untreated (cytokines but without TRAIL). (C) Cultures were treated and assayed as in A prior to the addition of TRAIL ( $800 \mathrm{ng} / \mathrm{ml}$ ) or TNF $\alpha$. The asterisk denotes results of TRAIL treatment with $P<0.0001$ (chi-squared test) when compared separately with all other samples. (D) Cultures were treated as in $\mathbf{C}$ except TRAIL, at concentrations displayed in the figure, were pre incubated with TRAIL-neutralizing soluble DR5 or soluble TNFR at $0.2 \mu \mathrm{g} / \mathrm{ml}$ for $1 \mathrm{~h}$ prior to addition to cultures. The asterisks denote results of TRAIL+soluble TNFR1 treatment with $P<0.0001$ (chi-squared test) when compared separately with untreated 0 ng of TRAIL control and cultures with the same concentration of TRAIL with soluble DR5 
treatment. ${ }^{26,27}$ We also showed that IFN $\gamma$ combined with TNF $\alpha$ and/or IL-1 $\beta$ pretreatment of TECs could provide death susceptibility to Fas-mediated apoptosis. ${ }^{12}$ In order to determine whether TRAIL-mediated apoptosis could be similarly induced by inflammatory cytokines we treated normal (obtained from non diseased tissue) primary TEC cultures for 4 days with various combinations of cytokines prior to addition of recombinant TRAIL to the culture medium. Cell death was measured $20 \mathrm{~h}$ after TRAIL administration. Figure $1 \mathrm{~A}$ shows the results of this assay. Substantial cell death occurred in cultures pretreated with the combination of TNF $\alpha$ and IL-1 $\beta$, with lower but significant levels of cell death detectable in IL-1 $\beta$ treated cultures. No cell death was observed with TNF $\alpha$ pretreatment. Saturating concentrations of IL- $1 \beta$ and TNF $\alpha$ were used suggesting the combination of the two cytokines results in a true synergistic effect rather than an additive effect. The additional pretreatment of these cultures with IFN $\gamma$ inhibited cell death in both circumstances (Figure 1A). The percentage of cell death occurring under these conditions varied in cultures derived from one patient sample to another but in all 10 samples tested the requirement for these particular cytokine combinations and only these combinations was absolute. The range of cell death was $23-$ $60 \%$ above background in IL-1 $1 / \mathrm{TNF} \alpha$ pretreated TRAIL treated samples with an average of $39 \%$ cell death. In these same 10 samples the addition of IFN $\gamma$ resulted in reduction of cell death ranging from $13.7-53.2 \%$ with an average of $35.7 \%$ when compared to TRAIL-mediated cell death after $\mathrm{TNF} \alpha / \mathrm{IL}-\beta$ treatment. All other experiments were performed on cultures derived from these 10 samples. To determine the optimum length of inflammatory cytokine treatment for induction of thyroid cell death susceptibility to TRAIL a timecourse of inflammatory cytokine treatment was performed. Figure 1B shows that detectable TRAIL-mediated cell death occurred after 4 days of cytokine pretreatment and declined slightly by day 5 . The requirement for at least 4 days exposure of the TEC cultures to cytokines TNF $\alpha$ and IL-1 $\beta$ combined with the rapid ( $\leqslant 4 \mathrm{~h}$, Figure $3 \mathrm{~B}$ and $\mathrm{C}$ ) cell death after treatment with TRAIL suggests that TRAIL is the primary death signal rather than TNF $\alpha$. To further distinguish whether the primary death signal is from TRAIL and not TNF $\alpha$ we reversed the treatment conditions by exposing the cells to TRAIL and IL-1 $\beta$ for 4 days prior to TNF $\alpha$ treatment and compared cell death to the previously defined conditions. Data in Figure $1 \mathrm{C}$ shows that pretreatment with TRAIL and IL$1 \beta$ does not impart susceptibility to TNF $\alpha$-mediated cell death. To demonstrate the specificity of the recombinant TRAIL preparation we used recombinant soluble DR5 to neutralize TRAIL. The results of this experiment shown in Figure 1D clearly demonstrate that soluble DR5 blocks TRAIL-induced cell death while soluble TNF R1 does not.

To definitively identify the apoptotic cells as thyroid follicular cells; we used an antibody that is specific for cytokeratin 18 (CK18), a marker for epithelial cells, but not fibroblasts (which commonly grow out of primary TEC cultures). Figure 2A shows CK18 expression in $90.6 \%$ of untreated cells and $82.2 \%$ of $\mathrm{TNF} \alpha$ and $\mathrm{IL}-1 \beta$ pretreated cells in thyroid cultures which were treated with TRAIL for induction of apoptosis (shown in Figure 2B). Figure 2B shows the results of staining the same cells used in Figure

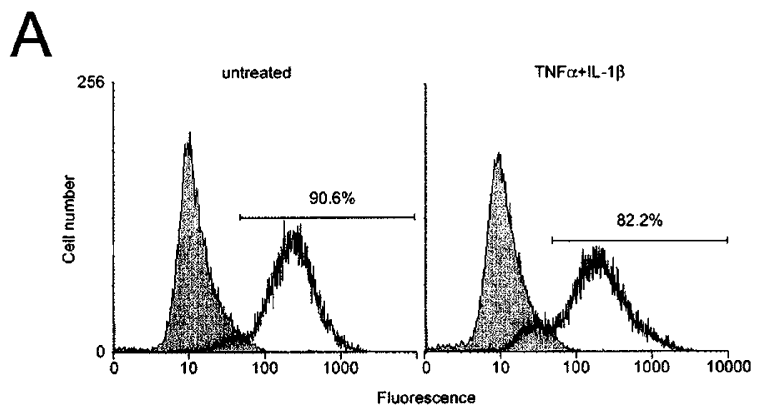

B

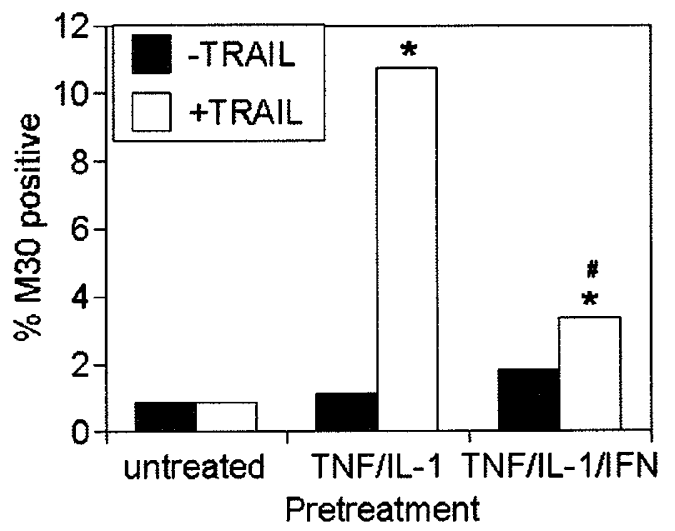

Figure 2 TRAIL induction of apoptosis occurs primarily in TECs. (A) Flow cytometry analysis of TECs treated for 4 days with cytokines prior to harvesting for staining and flow cytometry. The curve on the left of each panel represents the fluorescence of the control $A b$. The curve on the right of each panel represents the fluorescence of the CK18-specific Ab. (B) Flow cytometry analysis of TECs treated as above with the addition of TRAIL $6 \mathrm{~h}$ prior to harvesting of cells and staining with $M 30$ CytoDEATH ${ }^{\circledR}$ Ab. Asterisks denote results of TRAIL treatment with $P<0.0001$ (chi-squared test) when compared to cultures not treated with cytokines. \# Denotes $P<0.0001$ (chisquared test) when compared to the TRAIL and TNF/IL-1 treated culture

2A with the M30 CytoDEATH ${ }^{\circledR}$ Ab that specifically detects apoptotic epithelial cells by binding to caspase-cleaved CK18. $10.7 \%$ of the cells treated with cytokines and TRAIL were both epithelial and apoptotic in this assay. This is compared to only $1.1 \%$ of the cells treated with inflammatory cytokines but not treated with TRAIL and $<1 \%$ of the cells without inflammatory cytokine treatment regardless of TRAIL treatment. This documents that TRAIL induced apoptosis occurs in TECs. The addition of IFN $\gamma$ to the other inflammatory cytokines in this assay caused a small increase in background death (from 1.1 to $1.8 \%$ ) as was seen in most of our assays. But IFN $\gamma$ pretreatment significantly reduced TRAIL specific apoptosis from $10.7 \%$ to $3.3 \%$. Fibroblasts and vascular smooth muscle cells are common contaminants of TEC cultures and will overwhelm the epithelial cells over extended culture. Treatment of fibroblast or vascular smooth muscle cells derived from thyroid cultures with cytokines and TRAIL showed no cell death while remaining susceptible to Fas-mediated cell death (unpublished data).

Several assays were performed to further characterize the phenomenon of inflammatory cytokine-induced TRAIL- 

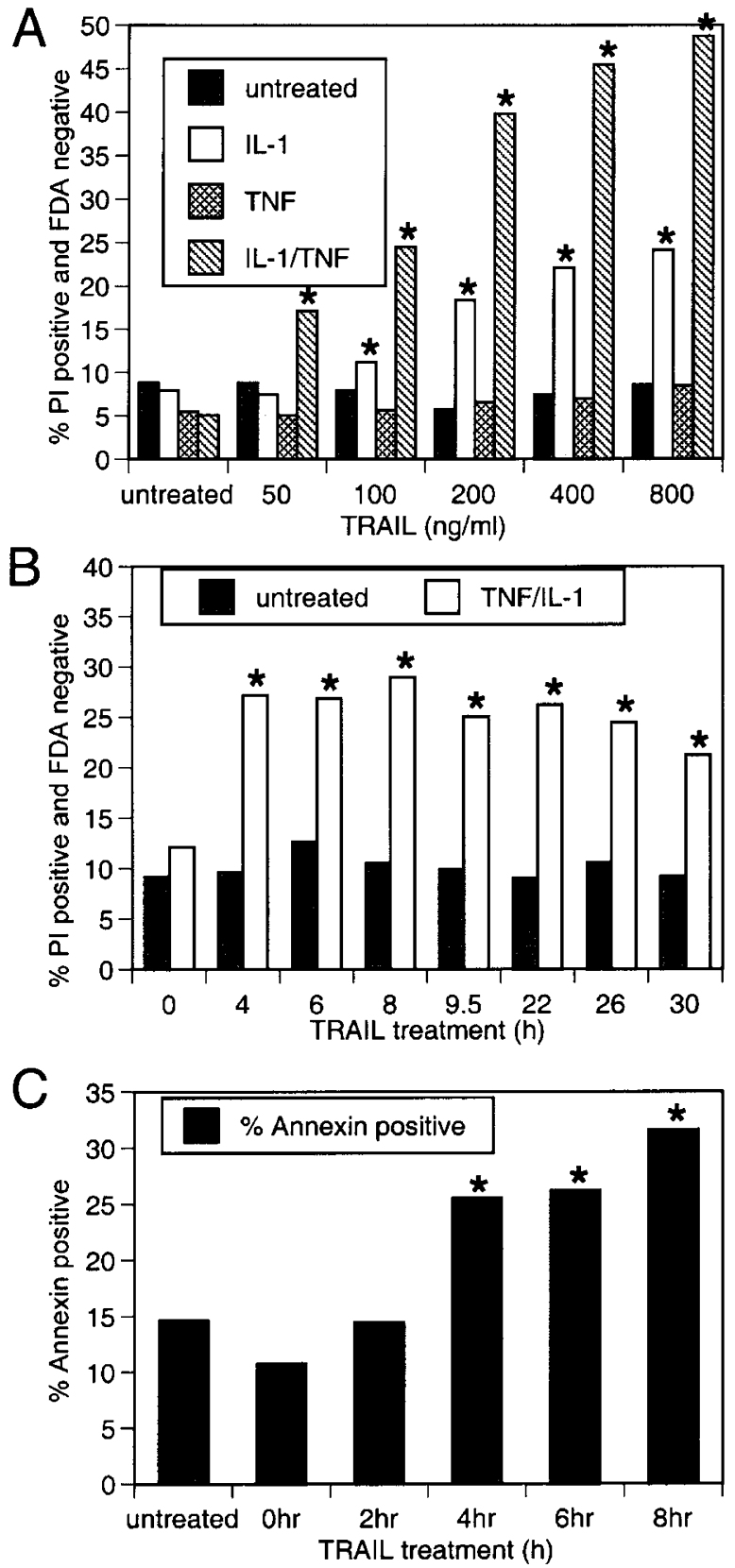

Figure 3 Further characterization of TRAIL induced cell death in TECs. (A) A dose-response of TRAIL cytotoxicity was performed on TEC cultures treated as described for Figure 1. Asterisks denote results of TRAIL treatment with $P<0.0001$ (chi-squared test) when compared separately with both the control sample (no cytokines) and untreated (cytokines but without TRAIL). (B) A timecourse of TRAIL cytotoxicity was performed on TEC cultures pretreated for 4 days prior to harvesting for staining and flow cytometry as described above. TRAIL $(800 \mathrm{ng} / \mathrm{ml})$ was added at the indicated times prior to cell harvest. Asterisks denote results of cytokine treatment with $P<0.0001$ (chi-squared test) when compared separately with both the control sample ( $0 \mathrm{~h}$ TRAIL treatment) and untreated (TRAIL but without cytokines). (C) Annexin V staining to determine apoptosis of TECs was performed on cultures treated for 3 days with TNF/IL1, and TRAIL was added at the indicated time prior to cell harvest for staining and flow cytometry as described above. Asterisks denote results of TRAIL treatment with $P<0.0001$ (chi-squared test) when compared to untreated cultures. TRAIL was also added immediately prior to harvest $(0 \mathrm{~h})$ to control for any apoptosis occurring after harvest but prior to flow cytometry quantitation. Only $\mathrm{PI}$ negative cells were used for quantitating Annexin V staining mediated apoptosis in normal TECs. Figure 3A shows a dose-response curve where TRAIL, in concentrations $\geqslant 50 \mathrm{ng} / \mathrm{ml}$, was capable of mediating the inflammatory cytokine induced cell death with maximum killing occurring at the highest concentration used $(800 \mathrm{ng} / \mathrm{ml})$. This range of concentrations is higher than that required for $\mathrm{CHX}$ induced susceptibility to TRAIL-mediated apoptosis. ${ }^{26}$ Figure $3 \mathrm{~B}$ shows that near maximum cell death occurs within $4 \mathrm{~h}$ and increases incrementally at $8 \mathrm{~h}$ where the level is maintained for at least $18 \mathrm{~h}$ more. This is likely due to rapid cell killing that reaches a limit at $4-8 \mathrm{~h}$. The dead cells then continue to remain detectable at later time points in this assay. The rapidity of killing is comparable to uninhibited Fas-mediated killing in other systems ${ }^{28,29}$ and in inflammatory cytokine treated thyroid cells. ${ }^{12}$ Annexin V staining of the outer leaflet of the plasma membrane was used to confirm that the dying thyroid cells were undergoing apoptosis. Figure 3C shows that significant Annexin $\mathrm{V}$ staining of intact cells occurred between 2 and $4 \mathrm{~h}$. This also confirms the time course data in Figure 3B.

\section{TRAIL receptor expression and regulation in TECs}

We have previously determined that DR4 and DR5 mRNA is expressed in untreated normal primary TECs. ${ }^{26}$ To determine whether regulation of expression of the TRAIL death receptors or decoy receptors may be involved in the control of thyroid cell apoptosis we performed RNase protection assays to determine relative mRNA expression levels in thyroid cell cultures treated with inflammatory cytokines. Figure 4A displays an autoradiogram showing relative levels of expression of DR4, DR5, DcR1 and DcR2 in thyroid cell cultures after 4 days treatment with various combinations of inflammatory cytokines. All four TRAIL receptor genes are expressed at the mRNA level regardless of cytokine treatment conditions. Also, all four genes appear to be regulated by certain combinations of cytokines, but increases in DR4 or DR5 mRNA levels do not correlate with conditions that promote TRAIL-mediated apoptosis (IL-1 $\beta$ or TNF $\alpha / \mathrm{IL}-1 \beta$ treatment). This suggests that death receptor up-regulation is not required for TRAIL death signaling, thus confirming our previous demonstration that susceptibility to TRAIL-mediated apoptosis could be induced by treatment with $\mathrm{CHX}$, which would block any increase in de novo receptor expression. ${ }^{26}$ Interestingly, DcR1 mRNA expression is decreased by $50 \%$ by the combination of TNF $\alpha$ with IL-1 $\beta$ when compared to the untreated control (as measured by densitometry and corrected for mRNA loading by comparison with GAPDH levels) and is unchanged or increased by other inflammatory cytokines including IL-1 $\beta$ alone (50\% increase). DcR2 mRNA expression, in conflict with its proposed function as an inhibitor of TRAIL-mediated apoptosis, increases dramatically under conditions of TRAIL susceptibility. To further characterize the regulation of TRAIL receptors we performed Western analysis on whole-cell lysates from TECs treated with inflammatory cytokines to determine relative levels of total protein expression. The results are shown in Figure 4B. DR5 protein was found present under all conditions but was increased significantly by treatment with IL-1 $\beta$ alone, TNF $\alpha$ alone and both in combination. DR5 was significantly reduced 
A

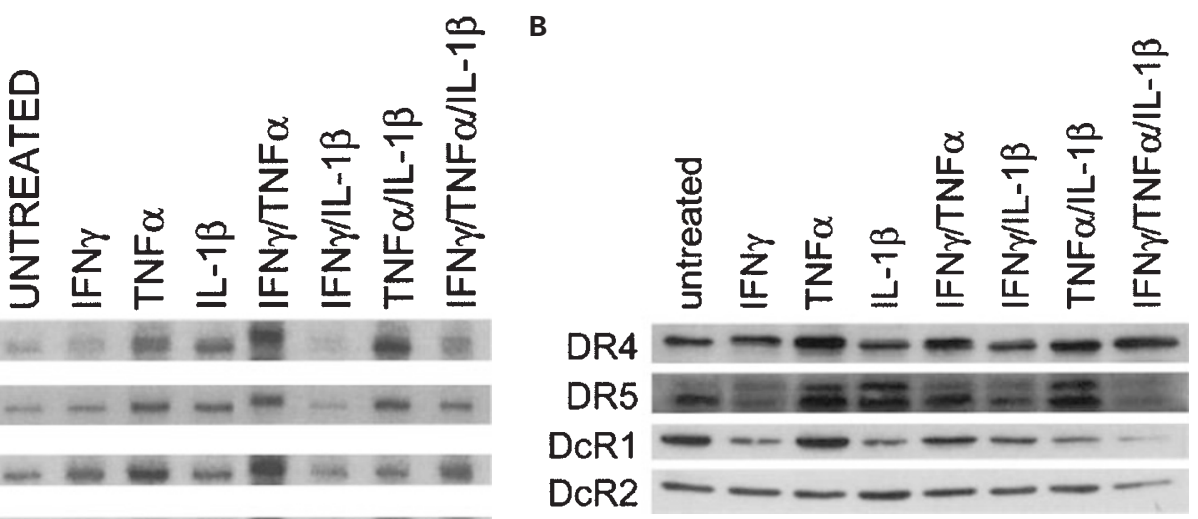

DcR2

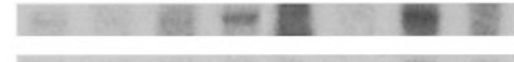

GAPDH

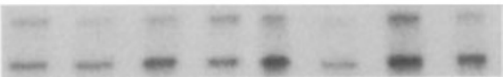

C

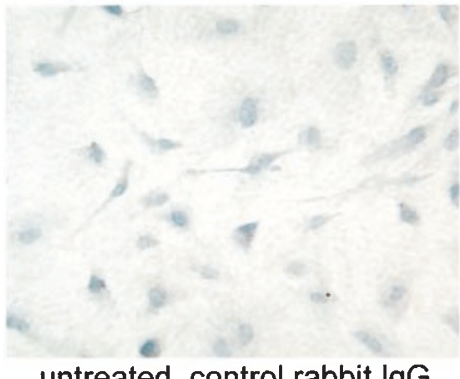

untreated, control rabbit $\lg G$

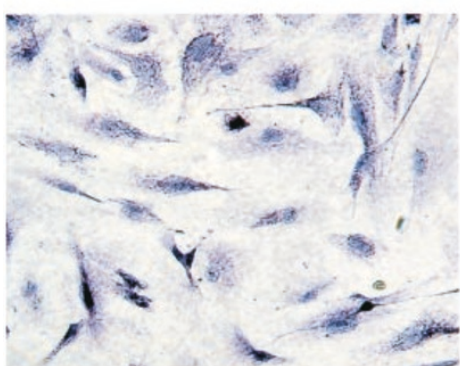

TNF-treated, anti-DR5

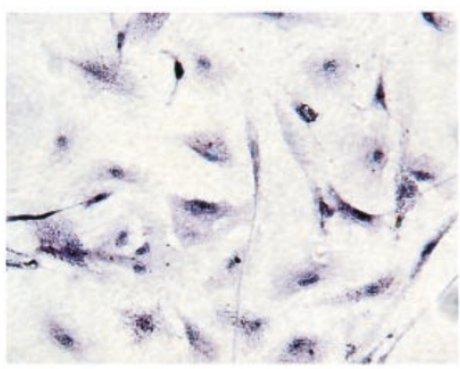

IFN-IL-1-treated, anti-DR5

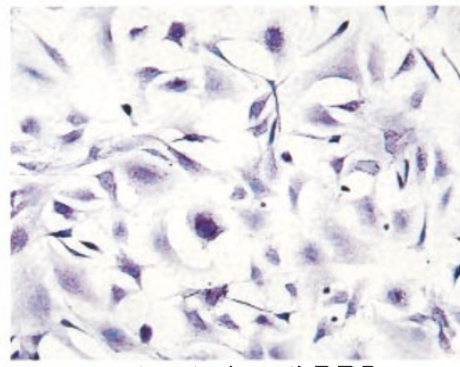

untreated, anti-DR5

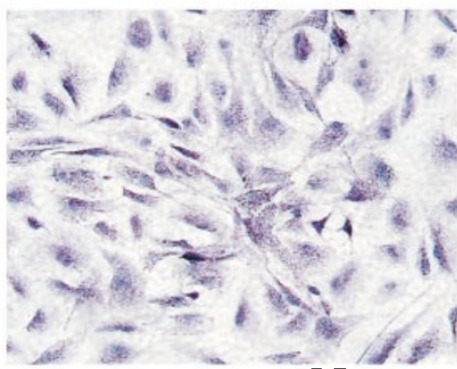

IL-1-treated, anti-DR5

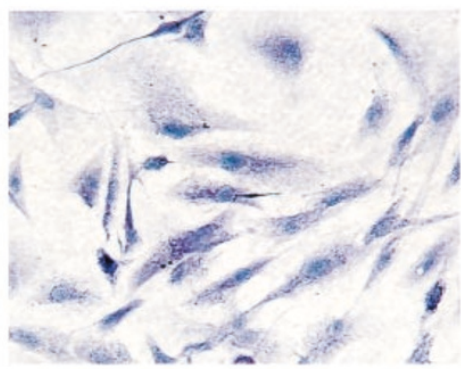

TNF/IL-1-treated, anti-DR5

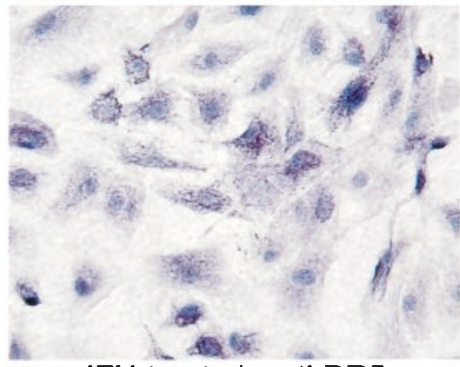

IFN-treated, anti-DR5

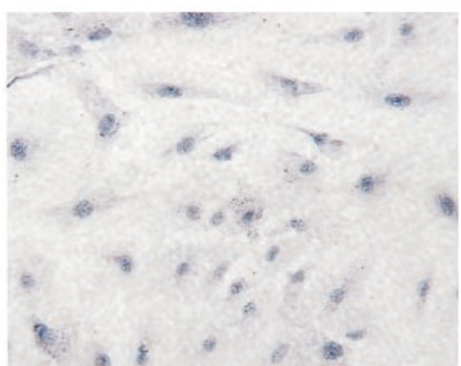

IFN/TNF-treated, anti-DR5

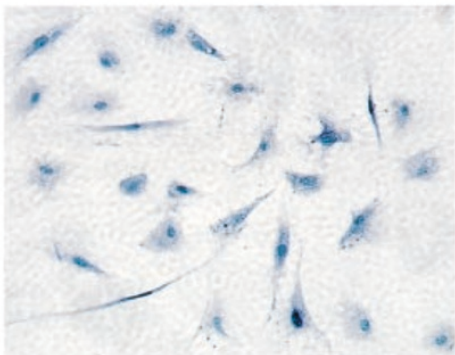

IFN/TNF/IL-1-treated, anti-DR5

Figure 4 Death receptor regulation in TECs by inflammatory cytokines. (A) RNase protection analysis was performed on mRNA isolated from TEC cultures treated for 4 days with the indicated cytokines. This experiment is representative of results from five independent experiments each using cultures derived from different patient samples. (B) Western analysis of TECs treated for 4 days with the indicated cytokines prior to harvesting and probed with Ab specific for the indicated TRAIL receptors. This experiment is representative of results from five independent experiments each using cultures derived from different patient samples. (C) Immunostaining of TECs treated for 4 days with the indicated cytokines prior to staining with DR5 antibody or control rabbit IgG. This experiment is representative of results from five independent experiments each using cultures derived from different patient samples. Original magnification=75 $\times$ 
after treatment with all three cytokines. DR4 and DcR2 were present under all treatment conditions but expression levels did not coincide with TRAIL sensitivity. DcR1 expression was reduced under conditions of TRAIL-mediated apoptosis (IL-1 $\beta$ alone, IL-1 $\beta$ and TNF $\alpha$ ) as well as other treatment conditions (IFN $\gamma$ alone, and all three cytokines combined). Only increases in DR5 total protein expression correlate with TRAIL susceptibility with the exception of TNF $\alpha$ treatment. To confirm this data, we immunostained to detect DR5 expression of inflammatory cytokine treated TECs in culture and observed the cells by light microscopy. The results in Figure $4 \mathrm{C}$ show high levels of DR5 expression in untreated cells and cells treated with each of the three cytokines alone or TNF $\alpha$ combined with IL-1 $\beta$. In contrast, treatment with both IFN $\gamma$ and $\mathrm{TNF} \alpha$ or all three cytokines greatly reduces DR5 staining. The reduction in staining appears most significant in cytoplasmic regions while some staining is maintained in or around the nucleus. The decrease in DR5 in the IFN $\gamma / \mathrm{IL}-1 \beta / \mathrm{TNF} \alpha$ treated cells may account for the resistance of these cells to TRAIL. Although DR5 expression levels increase under conditions of greatest TRAIL susceptibility and decrease under conditions of resistance this does not account for the significant levels of DR5 found under conditions of resistance. Combined, these results do not show an absolute correlation between TRAIL death receptor expression and TRAIL-mediated apoptosis.

To provide a more definitive clarification of a role for TRAIL receptor regulation in TRAIL-mediated apoptosis of TECs we determined their cell surface expression after treatment with cytokines. Figure 5 shows the results of flow cytometric determination of cell surface expression of DR5, DR4 and DcR1. DR4, DR5 and DcR1 were present in all untreated and cytokine treated cells. DcR2 was undetectable (unpublished data). Levels of DR4 were very low and decreased slightly with $\mathrm{TNF} \alpha / \mathrm{IL}-1 \beta$ treatment. This sug-
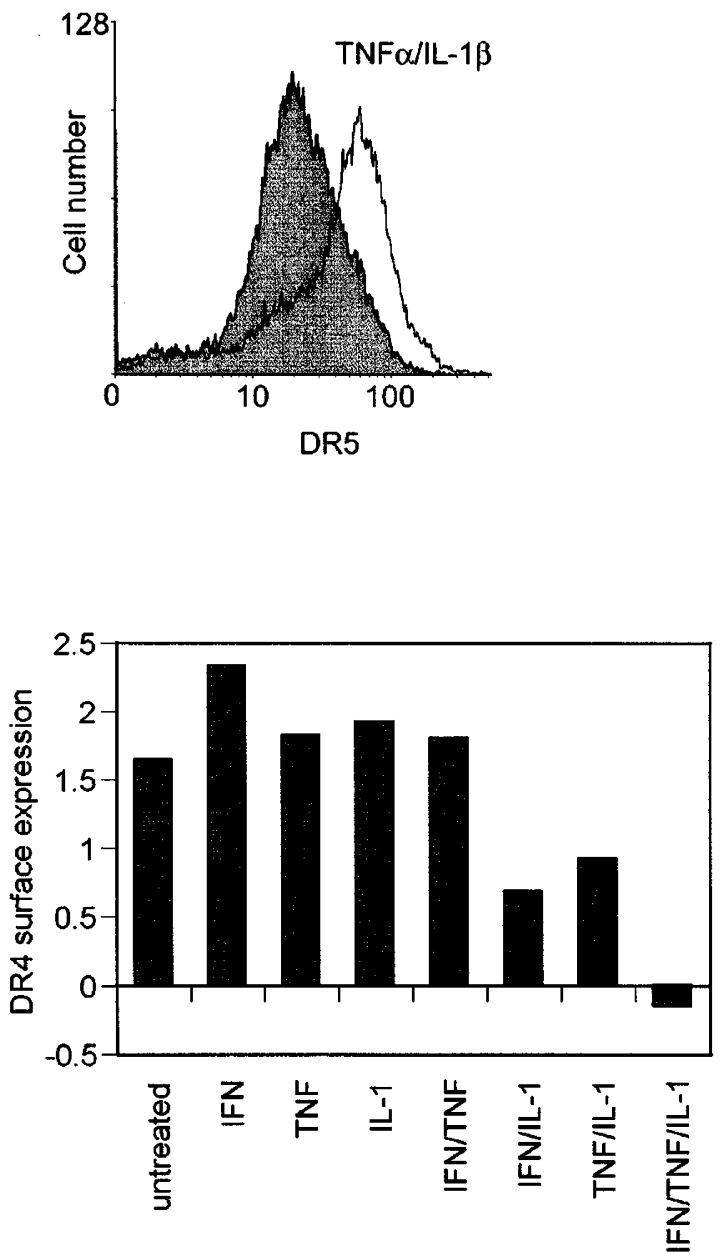

Cytokine pretreatment
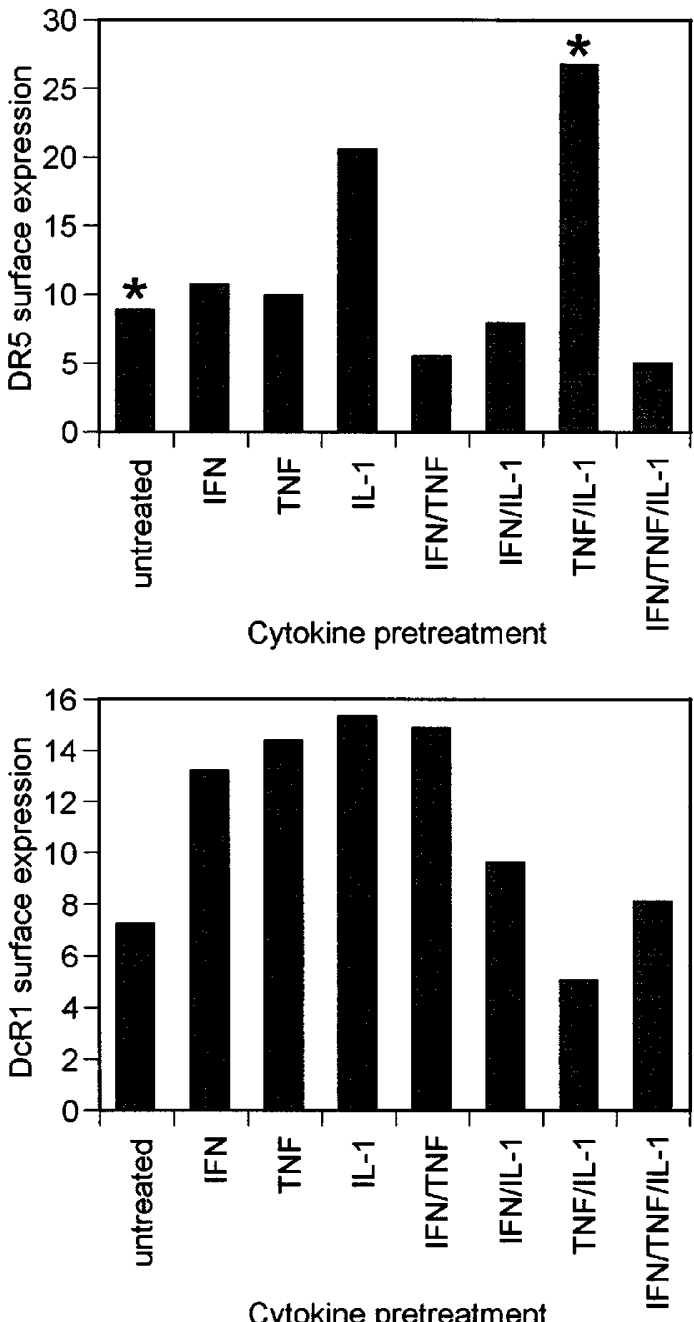

Figure 5 Flow cytometric determination of cell surface expression of DR5, DR4 and DcR1. TECs were treated with the indicated cytokines for 4 days prior to harvesting for flow cytometry. Upper left panel shows a representative histogram of DR5 Ab specific fluoresence for untreated cells (filled curve) and TNF $\alpha$ /LL-1 $\beta$ treated cells (open curve). Upper right, lower left and lower right panels show graphically the specific mean channel fluorescence for the indicated specific Ab with control Ab fluorescence subtracted for each cytokine treatment. Asterisks indicate the two data points derived from the data shown in the upper left panel. These experiments are representative of results from five independent experiments each using cultures derived from different patient samples 
gests DR4 does not play a role in TRAIL-mediated apoptosis in TECs. DR5 cell surface levels increased significantly with $\mathrm{IL}-1 \beta$ and more so with $\mathrm{IL}-1 \beta / \mathrm{TNF} \alpha$ treatment and dropped to below untreated cell levels when IFN $\gamma$ was added to either IL-1 $\beta$ or IL-1 $\beta / T N F \alpha$. Curiously, IFN $\gamma$ also slightly lowered DR5 levels in combination with TNF $\alpha$ but not by itself. This suggests the survival signal given by IFN $\gamma$ that results in the suppression of cell surface DR5 requires an additional signal provided by either TNF $\alpha$ or IL-1 $\beta$. DcR1 cell surface levels were suppressed by the IL-1 $\beta /$ TNF $\alpha$ treatment and returned to normal levels with the further addition of IFN $\gamma$. This is in agreement with its potential role as an inhibitor of TRAIL-mediated apoptosis. Each cytokine alone increased DcR1 expression but IFN $\gamma$ combined with either IL-1 $\beta$ or TNF $\alpha$ suppressed DcR1 expression. The greatest DR5 induction occurs under the same conditions as the greatest suppression of DcR1 and this correlates with the conditions of greatest sensitivity to TRAIL-mediated apoptosis.

To further define the role of subcellular location of TRAIL receptors in TRAIL-mediated apoptosis we performed confocal microscopy on cytokine treated TECs. Figure 6 displays the results of this analysis. DR5 expression is present regardless of cytokine treatment and is mostly intracellular. In agreement with the flow cytometry data, cell surface DR5 appears to increase with IL-1 $\beta /$ TNF $\alpha$ treatment and decrease with the further addition of IFN $\gamma$ when comparing relative intensity of surface staining to intracellular staining. DcR1 surface expression also shows agreement with the flow cytometry data as increased relative fluorescence is shown at the junctions of cells untreated and IFN $\gamma / \mathrm{IL}-1 \beta / \mathrm{TNF} \alpha$ treated cells although most fluorescence is intracellular. Decreased DcR1 expression occurs after IL- $1 \beta / \mathrm{TNF} \alpha$ treatment.

\section{DR5 transmits the apoptotic signal to IL-1 $\beta / T N F \alpha$ treated TECs}

During the course of our investigations we determined that a DR5-specific polyclonal Ab produced in goat (R\&D Systems lot
\#BVQ02) had the ability to act as an agonist for inducing apoptosis. This agonist Ab was specific for DR5 as soluble DR5 was able to block this activity while soluble DR4 and TNF R1 were not (unpublished data). As shown in Figure 7 the DR5 agonist $\mathrm{Ab}$ induces apoptosis in IL-1 $\beta / \mathrm{TNF} \alpha$ treated TECs and this activity is suppressed by the further addition of IFN $\gamma$. Soluble DR5 was able to neutralize the effects of this Ab while soluble TNF R1 was not, thus proving its specificity. This is identical to TRAIL-mediated apoptosis of these cells. This data along with the DR5 cell surface expression data strongly suggests that TRAIL acts through DR5 to induce apoptosis in TECs.

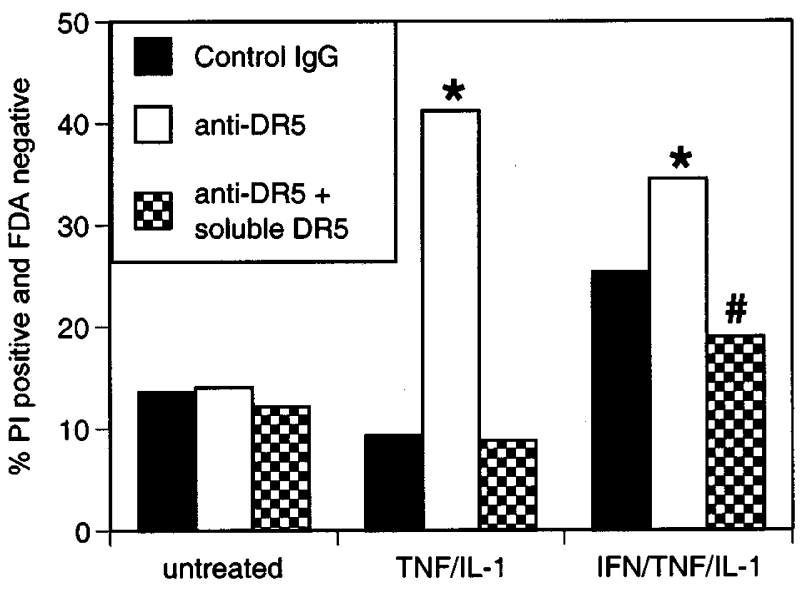

Cytokine pretreatment

Figure 7 Cell death in TECs is induced by a DR5-specific agonist antibody. TECs pretreated with the indicated cytokines for 4 days were treated with control goat IgG or goat anti-DR5 antibody with or without pre incubation for $1 \mathrm{~h}$ with soluble DR5. Results were quantitated as in Figure 1. An asterisk denotes the results of anti-DR5 treatment with $P<0.0001$ (chi-squared test) when compared to control IgG treated cultures and anti-DR5+soluble DR5 treatments from all cytokine pretreatments. The \# symbol denotes the results of anti-DR5+soluble DR5 treatment with $P<0.0001$ (chi-squared test) when compared to anti-DR5 treatment alone with the same cytokine pretreatment. This experiment is representative of results from three independent experiments each using cultures derived from different patient samples
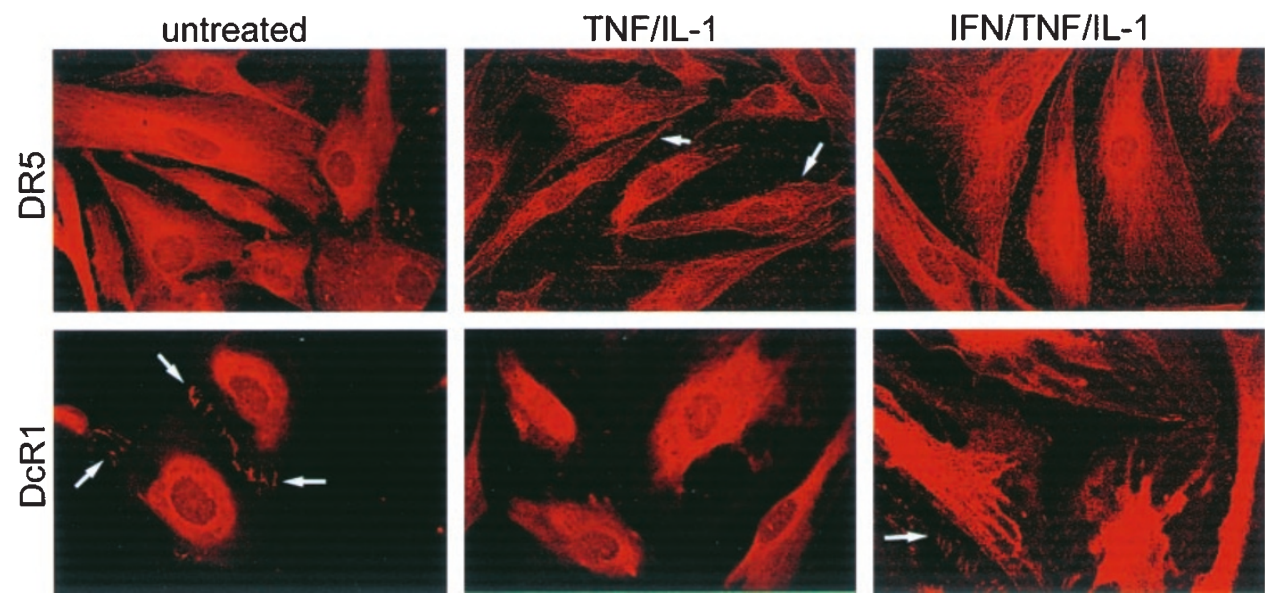

Figure 6 Laser scanning confocal microscopy of TECs stained for DR5 and DcR1 expression after 4 days treatment with the indicated cytokines. Arrows indicate cell surface staining. This experiment is representative of results from five independent experiments each using cultures derived from different patient samples 


\section{DR5, DcR1 and TRAIL are present in normal and thyroiditis glands}

To determine the potential for TRAIL-mediated apoptosis in vivo we endeavored to document DR5 and DcR1 expression in normal and diseased thyroids. To demonstrate the presence of DR5 and DcR1 in the thyroid we performed immunohistochemical staining of paraffin embedded thyroid tissue sections from patients with chronic autoimmune thyroiditis and compared staining with sections from normal thyroid lobes contralateral to the cancerous lobe in patients with thyroid cancer. As shown in Figure 8, DR5 and DcR1 are present and strongly expressed in all TECs regardless of whether they are normal or involved in thyroiditis. DR5 and DcR1 staining was detected in all thyroid follicles including those undergoing destruction. A significant portion of the infiltrating lymphocytic cells in the thyroiditis tissue also express both receptors. These results were confirmed using a second $\mathrm{Ab}$ specific for a different epitope of DR5 (unpublished observation). We have previously shown that TRAIL mRNA is expressed in inflammatory cytokine treated thyroid cells in culture. ${ }^{26}$ Determining the presence of TRAIL protein in the thyroid may suggest a mechanism for thyroid destruction in autoimmune thyroiditis. To determine whether TRAIL is expressed in vivo we immunohistochemically stained sections from the same thyroid tissue used in the experiments shown in Figure 8. Figure 9 shows TRAIL expression in follicular cells from both normal and thyroiditis-derived glands. Few, if any, lymphocytic cells expressed TRAIL (unpublished observation).

\section{Discussion}

The data presented here demonstrate that TRAIL-mediated apoptosis of TECs is regulated by inflammatory cytokines. IL$1 \beta$ alone and in combination with TNF $\alpha$ induces sensitivity to TRAIL, while the further addition of IFN $\gamma$ makes these cells resistant to apoptosis induced by TRAIL. This is the first reported demonstration of IL- $1 \beta$ induction of TRAIL sensitivity, TNF $\alpha /$ IL-1 $\beta$ synergy in inducing TRAIL sensitivity and inhibition of TRAIL sensitivity by IFN $\gamma$. This pattern of TRAIL sensitivity correlates with levels of cell surface expression of TRAIL receptors. IL-1 $\beta /$ TNF $\alpha$ enhancement of DR5 surface expression provides the mechanism of TRAIL sensitivity. IFN $\gamma$ counteracts this activity by suppressing DR5 surface expression, thus preventing apoptotic signal transduction. We have further documented that the signal is mediated through DR5 by the use of a DR5 specific agonist Ab. These data are the first to demonstrate the induction of cell surface DR5 by IL-1 $\beta$ alone or in synergy with $\operatorname{TNF} \alpha$. This is also the initial demonstration of regulation of DcR1 cell surface expression levels by any treatment of any cell type especially primary cells. We also show for the first time the in vivo presence of DR5, DcR1 and TRAIL in the thyroid gland in both normal thyroid follicles and follicles undergoing autoimmune destruction.

Many articles have been published describing an apparent lack of correlation of TRAIL receptor expression (both death and decoy receptors) with susceptibility to TRAIL. ${ }^{30-37}$ The authors of these articles have suggested, without definitive proof, that either downstream signal inhibitors are involved or endogenous levels of decoy

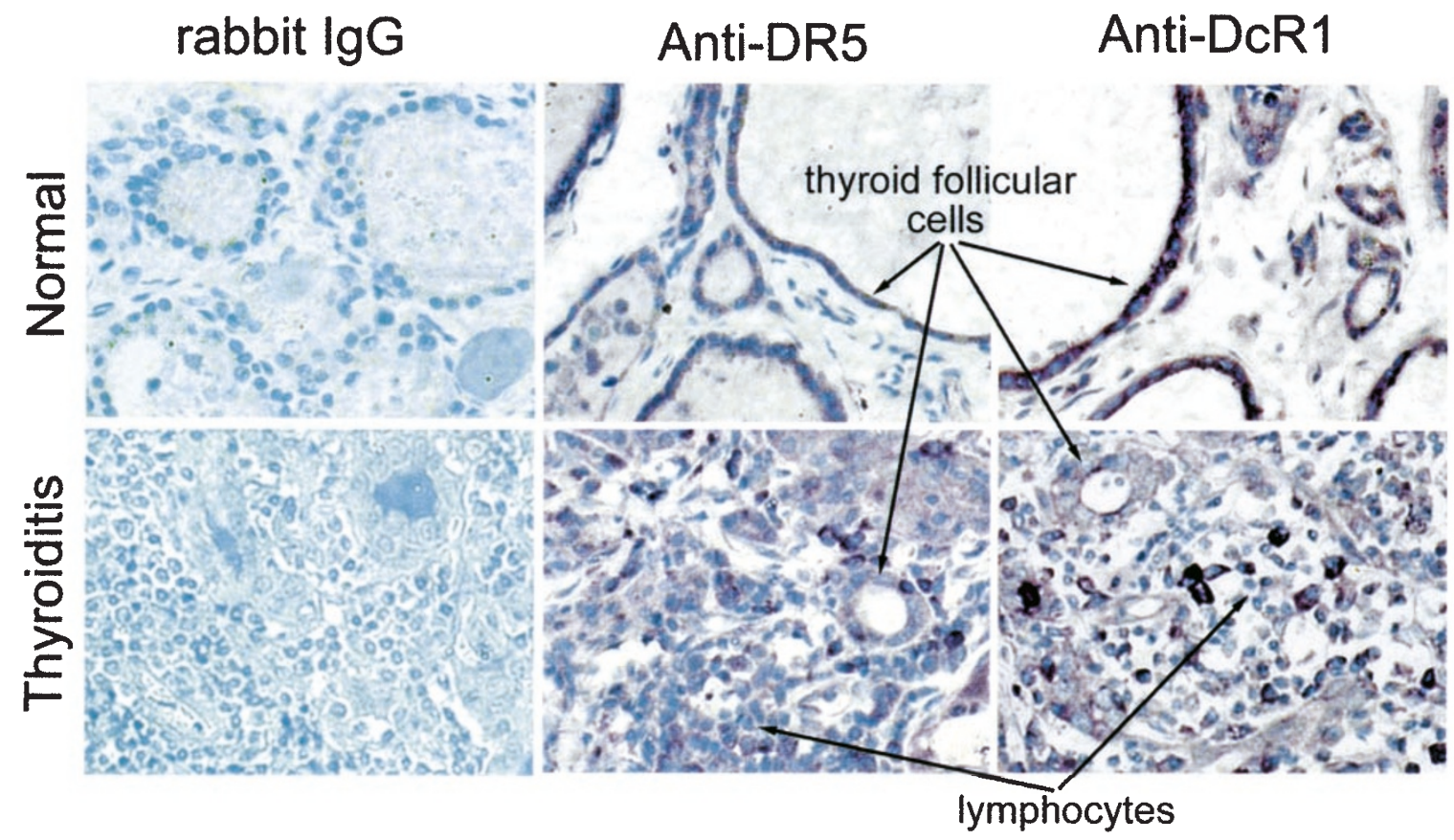

Figure 8 TRAIL receptor expression in the thyroid Immunohistochemical staining of thyroid sections was performed on samples from a normal thyroid (upper panels) and from a patient with chronic autoimmune thyroiditis (lower panels) using Ab specific for DR5 (middle panels) and DcR1 (right panels) compared to a rabbit control $\mathrm{Ab}$ (left panels). Original magnification $=100 \times$ 


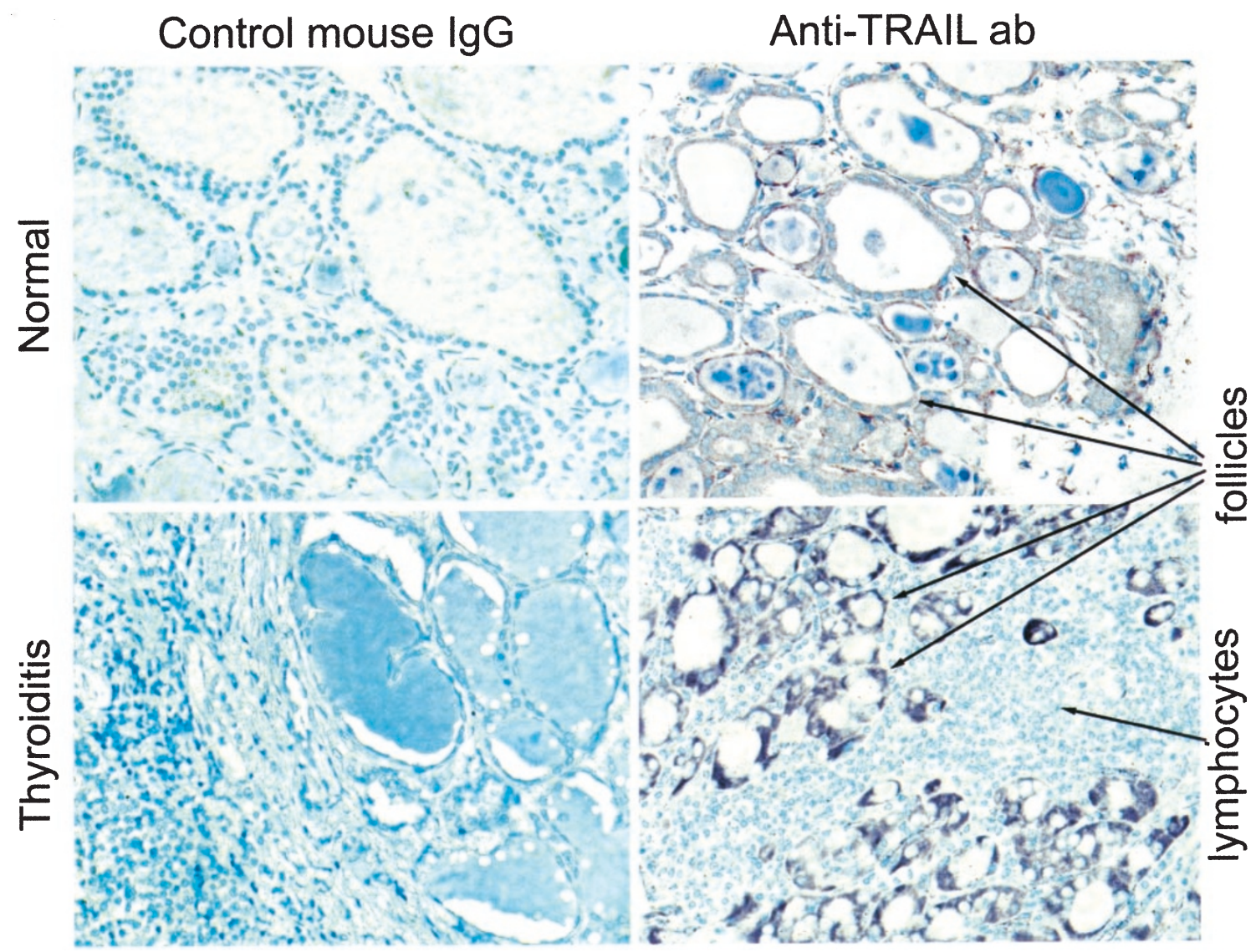

Figure 9 TRAIL expression in the thyroid. Immunohistochemical staining was performed on sections from the same samples used in Figure 8 using an Ab specific for TRAIL (right panels) and a mouse IgG control Ab (left panels). Original magnification $=100 \times$

receptors are not involved in TRAIL-mediated apoptosis regulation. Our results suggest that these inconsistencies are likely due to simply measuring mRNA or total protein, which are not reflective of the functional form of the receptor on the cell surface. Others have shown constitutive surface expression of TRAIL death receptors on cells that were not susceptible to TRAIL. ${ }^{38}$ This suggests the possibility of an intracellular inhibitor of the TRAIL pathway. Our data regarding inflammatory cytokine regulation of TRAIL-induced apoptosis does not rule out the possibility of an intracellular inhibitor of this pathway. We have demonstrated in TECs that cytokine regulated apoptosis was not due simply to an increase in total expression of the TRAIL death receptors DR4 and DR5. This agrees with our previous findings that showed inhibition of protein synthesis in these cells could also enable the TRAIL pathway, possibly through selective loss of a labile inhibitor. ${ }^{26}$ This inhibitor may act by preventing release of cytoplasmic DR5 to the cell surface. Expression levels of known inhibitors of apoptosis BCL-2, BCL-X, XIAP, NAIP, ClAP1, ClAP2 and cFLIP in our system are not regulated in a manner that correlates with susceptibility to TRAIL, neither does expression of pathway components Caspase-8, Caspase 10, Caspase 3 and FADD (unpublished data).
DcR1 is a TRAIL decoy receptor that when over expressed has been shown to inhibit TRAIL receptormediated apoptosis. ${ }^{39,40}$ Activity of endogenous levels of cell surface DcR1 have not been well characterized. DcR1 mRNA and cell surface expression in TECs is suppressed by the same conditions that induce apoptosis susceptibility. This suggests DcR1 suppression may be a mechanism of apoptosis regulation in these cells. Although we cannot definitively prove that DcR1 is involved in TEC apoptosis regulation because its down regulation coincides with DR5 upregulation, it is on the cell surface and accessible to TRAIL binding. This could hypothetically reduce the amount of TRAIL available for binding to DR5 initiating the apoptotic signal. ${ }^{39-41}$

Apoptosis plays an important role in autoimmune disease. ${ }^{3,42-44}$ Death receptor pathways other than Fas and TNFR-1 have only recently become recognized as potentially important in disease pathogenesis. ${ }^{45,46}$ Specifically, inhibition of TRAIL has been implicated in exacerbation of rheumatoid arthritis and experimental autoimmune encephalomyelitis in animal models. ${ }^{47,48}$ The presence of TRAIL, DR5 and DcR1 in an inflamed thyroid and regulation of the TRAIL apoptosis signaling pathway by the inflammatory cytokines TNF $\alpha, \mathrm{IL}-1 \beta$ and IFN $\gamma$, which 
are known to be present in autoimmune thyroids, strongly suggests a role for these proteins in autoimmune thyroid disease. ${ }^{49}$ In addition, the presence of all three of these proteins in a normal thyroid strongly supports our view that this pathway is highly regulated and is normally inhibited. ${ }^{49}$

We have now shown that inflammatory cytokines IFN $\gamma$, TNF $\alpha$ and IL- $1 \beta$, regulate TEC susceptibility to apoptosis by both Fas $^{12}$ and TRAIL-mediated mechanisms, but this occurs only with specific and unique combinations of these cytokines. Interestingly, the conditions of maximum Fasmediated apoptosis (IFN $\gamma$ combined with either TNF $\alpha$ or IL$1 \beta$, and all three combined) are different and exclusive of the conditions of maximum TRAIL-mediated apoptosis (TNF $\alpha$ with IL-1 $\beta$ ). For example the addition of all three of these cytokines increases Fas-induced apoptosis but specifically inhibits TRAIL-induced apoptosis. This suggests that the inhibition of the Fas and TRAIL apoptosis pathways occurs prior to their convergence at the common apoptotic pathway and involves distinct inhibitors that are differentially regulated. This suggests these complementary activities must have an important function and the cytokine milieu in the thyroid follicle microenvironment would be important for regulating these functions. In addition to TRAIL susceptibility, TRAIL expression is induced in TECs by certain combinations of cytokines. By mRNA analysis all three cytokines stimulate low levels of TRAIL expression with the greatest induction occurring under conditions of maximum susceptibility to Fas-mediated apoptosis (IFN $\gamma$ combined with either TNF $\alpha$ and/or IL-1 $\beta) .{ }^{12,26}$ This suggests TECs are becoming susceptible to FasL when they are simultaneously acquiring the ability to kill cells susceptible to TRAIL. Based on these observations we have proposed several models for the involvement of TRAIL in destructive thyroiditis. ${ }^{49,50}$ These are similar to models proposed for FasL. ${ }^{11,51}$ (1) Inflammatory cytokine sensitized TECs may be killed by autoimmune cells expressing TRAIL, (2) TRAIL expressed by TECs may be involved in a defense mechanism for the TECs to resist attack by killing autoimmune lymphocytes, or alternatively, (3) TRAIL expressed by TECs may result in self destruction. Models 1 and 3 would result in loss of thyroid hormone production by the thyroid gland and result in Hashimoto's disease. Model 2 would result in protection of the thyroid gland despite the presence of autoimmune cells, a situation which occurs in Graves' disease. Each of these scenarios is possible but depends on the presence of a particular combination of inflammatory cytokines. We have described these models in greater detail in recent reviews. ${ }^{49,50}$ These models are not necessarily exclusive of each other. Future experiments will distinguish these scenarios.

It has recently been reported that some, but not all, TRAIL preparations can kill normal human hepatocytes depending on the purification method and presence of epitope tags. ${ }^{52,53}$ Our TRAIL was prepared by a method likely to produce hepatotoxicity. ${ }^{54}$ We are currently attempting to obtain the non-hepatotoxic TRAIL for tests on TECs. Regardless, the cytokine regulation of DR5 and $\mathrm{DcR} 1$, as well as the activity of the agonist DR5 Ab, are independent of the TRAIL prep. Based on this information it will be of interest to determine whether IFN $\gamma$ treatment can protect normal human hepatocytes from TRAIL-mediated apoptosis in a manner similar to its rescue of TECs.

In summary, we have outlined mechanisms of TRAILmediated apoptosis in thyroid epithelial cells. This system of inducible and repressible TRAIL-mediated apoptosis will provide a useful experimental model for further study of the regulation of this pathway. We have also demonstrated the presence of the involved proteins (DR5, DcR1, TRAIL) in vivo. This observation documents the relevance of these investigations to human disease states. Studies with animal models including transgenic mice as well as more in-depth studies in humans will be needed to clarify the role these pathways perform in thyroid disease.

\section{Materials and Methods}

\section{Cell culture}

Normal thyroid tissue was obtained from patients at thyroidectomy from the uninvolved, contralateral lobes of thyroids with tumors. All excised tissues were prepared for cell culture as previously described. ${ }^{27}$ The primary cultures were passaged in CellGro Complete media (Mediatech, Herndon, VA, USA) supplemented with 10\% NuSerum IV (Collaborative Biomedical Products, Bedford, MA, USA), $100 \mathrm{units} / \mathrm{ml}$ penicillin and $100 \mu \mathrm{g} / \mathrm{ml}$ streptomycin. CK18 staining was performed with anti-CK18 Ab (Chemicon) and quantitated by flow cytometry, as described below, to determine TEC purity and only cultures that were $>90 \%$ positive were used for experiments.

\section{Cytokines, agonist Abs and soluble receptors used in cell culture}

Cells were treated with cytokines, as described in the figure legends at the following concentrations: IFN $\gamma(100 \mathrm{u} / \mathrm{ml}$ ) (Roche Molecular Biochemicals), TNF $\alpha$ (50 ng/ml) (Collaborative Biomedical Products), IL-1 $\beta \quad(50 \mathrm{u} / \mathrm{ml})$ (Sigma Chemical Co.). TRAIL (a kind gift of $A$ Chinnaiyan) was affinity purified as described ${ }^{54}$ from bacterial lysates of cells transfected with the plasmid pET15b-His-FLAG-TRAIL. The purity of the TRAIL preparation was confirmed by silver stained SDSPAGE and limulus amebocyte lysate assay. ${ }^{54}$ Agonist anti-DR5 Ab (R\&D Systems) was used at $500 \mathrm{ng} / \mathrm{ml}$ to induce apoptosis specifically through DR5. Soluble human DR5/IgG Fc chimera, used as specific inhibitor of TRAIL, and human TNF-R1/lgG FC chimera were kindly provided by $R \& D$ Systems.

\section{RNase protection assays}

RNA was isolated from cells using Trizol Reagent according to the manufacturer's protocol (GibcoBRL, Grand Island, NY, USA). RiboQuant MultiProbe RNase Protection Assay System (Pharmingen, San Diego, CA, USA) was used for the detection and quantitation of multiple, specific mRNA species. ${ }^{32} \mathrm{P}$-labeled antisense RNA probes were prepared using the Human Apoptosis hAPO-3d template set (Pharmingen), which included probes for human TRAIL, DR4, DR5, DcR1, DcR2 and GAPDH. This was performed as described previously ${ }^{27}$ according to the manufacturer's protocol. Briefly, the probes were hybridized with $2-5 \mu \mathrm{g}$ total RNA from treated 
thyrocytes. After hybridization, the samples were subjected to RNase treatment followed by purification of RNase-protected probes. The protected probes were resolved on a $5 \%$ denaturing polyacrylamide gel. We quantified transcripts by autoradiography followed by densitometry. Relative amounts of message were corrected for RNA loading by comparison with the GAPDH band intensity for each sample.

\section{Determination of cell viability and apoptosis}

Cell viability was determined by staining with fluorescein diacetate (FDA) and propidium iodide (PI) quantitated by flow cytometry as described by Killinger et al. ${ }^{55} \mathrm{PI}$ positive and FDA negative cells were considered dead. Flow cytometric analysis of caspase-specific proteolytic cleavage of cytokeratin 18 (M30 CytoDEATH ${ }^{\mathbb{R}}$ monoclonal $\mathrm{Ab}$ ) and Annexin V binding (Annexin V-FLUOS staining kit) were used as described by the manufacturer to confirm that apoptosis had occurred (both from Roche Molecular Biochemicals).

\section{Western analysis}

Total DR4, DR5, DcR1 and DcR2 protein expression in thyroid cell cultures was determined by Western analysis. Cells were rinsed with PBS and lysed in RIPA buffer with protease inhibitors (Complete, Roche Molecular Biochemicals), insoluble material was removed by centrifugation and supernatants stored frozen at $-20^{\circ} \mathrm{C}$ until used for Western analysis. Protein in the lysates was quantitated by BCA protein assay kit (Pierce Chemical Co., Rockford, IL, USA) and equivalent amounts of each sample were electrophoretically separated on a $10.0 \%$ SDS-polyacrylamide gel after addition of sample buffer and transferred to nitrocellulose as described. ${ }^{27}$ Primary Abs used were as follows: mouse anti-DR4 monoclonal Ab (Imgenex) at $2.0 \mu \mathrm{g} / \mathrm{ml}$, goat anti-DR5 polyclonal Ab (R\&D Systems) at $0.2 \mu \mathrm{g} / \mathrm{ml}$, rabbit anti-DcR1 polyclonal Ab (Affinity BioReagents) $2.0 \mu \mathrm{g} / \mathrm{ml}$ and rabbit anti-DcR2 polyclonal $A b$ (ProSci) at $0.5 \mu \mathrm{g} / \mathrm{ml}$. Results were visualized by ECL (Amersham, Arlington Heights, IL, USA) followed by autoradiography and quantitated by densitometry.

\section{Flow cytometric determination of cytokeratin 18, DR5, DR4 and DcR1 expression}

Cytokeratin 18 expression was determined by $\mathrm{Ab}$ staining and quantitated by flow cytometry as described by manufacturer (Roche Molecular Biochemicals). Briefly, trypsinized cells were washed and fixed in ice-cold methanol overnight, washed in wash buffer (PBS, Triton X-100) and incubated for 15 min in blocking buffer (PBS, Triton $\mathrm{X}-100, \mathrm{BSA}$ ). Blocking buffer was replaced with anti-cytokeratin $18 \mathrm{Ab}$ diluted to $2.0 \mu \mathrm{g} / \mathrm{ml}$ in blocking buffer and incubated for $1 \mathrm{~h}$. Cells were then washed in washing buffer three times and resuspended in secondary Ab (anti-mouse FITC conjugate (Jackson ImmunoResearch) diluted to $1: 100$ in blocking buffer) and incubated for $30 \mathrm{~min}$, washed three times with wash buffer and resuspended in 0.5 PBS for flow cytometry as described below. The MOPC21 Ab (Sigma) was used as an isotype matched control Ab.

For detection and quantiation of DR5, DR4 and DcR 1 cell surface expression by flow cytometry, cytokine treated thyroid cells were made non adherent by incubation with $0.265 \mathrm{mM}$ EDTA in PBS, washed in PBS and incubated for $15 \mathrm{~min}$ in blocking solution (2\% normal horse serum, $1 \% \mathrm{BSA}$ in PBS) at $4^{\circ} \mathrm{C}$. Goat polyclonal anti-human DR5, DR4 or DcR1 Ab (R\&D Systems) was diluted in blocking solution to $5 \mu \mathrm{g} / \mathrm{ml}$ and cells were incubated with the $\mathrm{Ab}$ for $20 \mathrm{~min}$, at $4^{\circ} \mathrm{C}$. After washing in the blocking solution, FITC-conjugated anti-goat $F\left(a b^{\prime}\right)_{2}$ fragment
(Jackson ImmunoResearch) was used in 1:100 dilution for $20 \mathrm{~min}$, at $4^{\circ} \mathrm{C}$. Purified goat IgG (R\&D Systems) served as control Ab. Flow cytometry was performed and $2 \times 10^{4}$ cells were acquired for each sample and quantitated on a FACScalibur flow cytometry (Becton Dickinson, Franklin Lakes, NJ, USA).

\section{Immunostaining of thyroid sections and cultured cells}

DR5, DcR1 and TRAIL expression on human thyroid tissue sections was analyzed by immunohistochemical staining. Formalin-fixed, paraffin-embedded sections were obtained after pathological examination from normal thyroid glands and from patients with chronic autoimmune thyroiditis. Sections were deparaffinized with three rinses of xylene and rehydrated in ethanol. For antigen unmasking the slides were microwave-treated for $15 \mathrm{~min}$ in $0.01 \mathrm{M}$ citrate buffer $\mathrm{pH} 6.0$. Neutralization of endogenous peroxidases was performed by $30 \mathrm{~min}$ incubation of sections with $3 \% \mathrm{H}_{2} \mathrm{O}_{2}$ dissolved in methanol. Samples were blocked with $5 \%$ goat or horse serum (depending on the secondary $\mathrm{Ab}$ ) for $20 \mathrm{~min}$. DR5 expression was detected by rabbit polyclonal Ab (2019, ProSci Inc., Poway, CA, USA, and AF837, R\&D Systems, Minneapolis, MN, USA). Purified rabbit IgG Ab was used as a control (Jackson ImmunoResearch Laboratories, Inc, West Grove, PA, USA). Sections were incubated with rabbit Abs for $1 \mathrm{~h}$ at $5 \mu \mathrm{g} / \mathrm{ml}$ in $1.5 \%$ normal goat serum. After washing with PBS, the slides were incubated with biotinylated goat anti-rabbit $\lg G$ and detected using avidin-biotin complex kit with VIP substrate (Vector Laboratories, Inc. Burlingame, CA, USA). TRAIL expression was examined using mouse monoclonal Ab (66251A, Pharmingen, San Diego, CA, USA) and MOPC $141 \mathrm{Ab}$ as an isotype (IgG2b) matched control (M8894, Sigma), at $5 \mu \mathrm{g} / \mathrm{ml}$ in $1.5 \%$ normal horse serum for $1 \mathrm{~h}$. Secondary $\mathrm{Ab}$ for mouse Abs was biotinylated horse anti-mouse IgG Ab (BA-2000, Vector Laboratories, Inc. Burlingame, CA, USA). Detection was performed using $A B C$ and VIP substrate as described above. Slides were counterstained with methyl green and mounted with Permount (Sigma).

Staining of cultured thyroid cells was performed as described previously ${ }^{27}$ with the following changes: Ab for DR5 (ProSci Inc.) was used at a 1:500 dilution and detection was performed using an avidinbiotin complex kit with VIP substrate (Vector Laboratories, Inc.).

Laser scanning confocal microscopy of cultured thyroid cells was performed at the University of Michigan Microscopy and Image Analysis Laboratory on a Zeiss model LSM 510 microscope. For confocal microscopy, thyroid cells cultured in chamber slides were fixed in ice-cold methanol for $10 \mathrm{~min}$. Samples were blocked in $10 \%$ FBS for $20 \mathrm{~min}$ and the following Abs were used for the detection of TRAIL receptors: DR5 - rabbit polyclonal Ab (R\&D Systems), at $5 \mu \mathrm{g} /$ $\mathrm{ml}$ concentration and DcR1 - rabbit polyclonal Ab (ABR), $5 \mu \mathrm{g} / \mathrm{ml}$. The slides were incubated with the primary Abs overnight at $4^{\circ} \mathrm{C}$. After washing in PBS the cultures were incubated with Texas-Red-X conjugated anti-rabbit secondary Ab (Molecular Probes) at $10 \mu \mathrm{g} / \mathrm{ml}$ for $30 \mathrm{~min}$. The samples washed in PBS and mounted in Prolong Antifade mounting media (Molecular Probes) and stored at $4{ }^{\circ} \mathrm{C}$ until analysis.

\section{Computer software}

Graphing was performed using DeltaGraph 4.0 (DeltaPoint Inc., CA, USA). Flow cytometry data were analyzed by WinMDI 2.7 (Joseph Trotter URL http://facs.scripps.edu/). Densitometric quantitation of autoradiograms was performed using Quantity One (Bio-Rad). Statistical analysis was performed using Microsoft Excel. 


\section{Acknowledgements}

We thank T Stokes, K Borgerson, E Phelps and D Deigert for technical assistance, Dr. A Chinnaiyan for the endotoxin-free TRAIL and P Arscott and Dr. S Wang for valuable discussions. Support for this work came from the National Institutes of Health Grants R01 A137141 to JR Baker and P60DK20572.

\section{References}

1. Arends MJ and Wyllie AH (1991) Apoptosis: mechanisms and roles in pathology. Int. Rev. Exp. Pathol. 32: 223-254

2. VauxDLand Korsmeyer SJ (1999) Cell death in development. Cell. 96:245-254

3. Rudin CM and Thompson CB (1997) Apoptosis and disease: regulation and clinical relevance of programmed cell death. Annu. Rev. Med .48: 267-281

4. Scaffidi C, Kirchoff S, Krammer PH and Peter ME (1999) Apoptosis signaling in lymphocytes. Curr. Opin. Immunol. 11: 277-285

5. Ohsako $S$ and Elkon KB (1999) Apoptosis in the effector phase of autoimmune diabetes, multiple sclerosis and thyroiditis. Cell Death Differ. 6: 13-21

6. Foulis AK (1996) The pathology of the endocrine pancreas in type 1 (insulindependent) diabetes mellitus. APMIS. 104: 161-167

7. Yamada K, Takane-Gyotoku N, Yuan X, Ichikawa F, Inada C and Nonaka K (1996) Mouse isletcell lysis mediated by interleukin-1-induced Fas. Diabetologia 39: $1306-1312$

8. BenoistC and Mathis D (1997) Cell death mediators in autoimmune diabetes - no shortage of suspects. Cell 89:1-3

9. Chervonsky AV, Wang Y, Wong FS, Visintin I, Flavell RA, Janeway Jr CA and Matis LA (1997) The role of Fas in autoimmune diabetes. Cell 89: 17-24

10. Su X, Hu Q, Kristan JM, Costa C, Shen Y, Gero D, Matis LA and Wang Y (2000) Significant role for fas in the pathogenesis of autoimmune diabetes. J. Immunol. 164: 2523-2532

11. Giordano C, Stassi G, De Maria R, Todaro M, Richiusa P, Papoff G, Ruberti G, Bagnasco M, Testi R and Galluzzo A (1997) Potential involvement of Fas and its ligand in the pathogenesis of Hashimoto's thyroiditis. Science 275: 960-963

12. Bretz JD, Arscott PL, Myc A and Baker Jr JR (1999) Inflammatory cytokine regulation of Fas-mediated apoptosis in thyroid follicular cells. J. Biol .Chem. 274: $25433-25438$

13. French LE and Tschopp J (1997) Thyroiditis and hepatitis: Fas on the road to disease [news; comment]. Nat. Med. 3: 387-388

14. Borgerson KL, Bretz JD and Baker Jr JR (1999) The role of Fas-mediated apoptosis in thyroid autoimmune disease. Autoimmunity 30: 251-264

15. Kotani T, Aratake $Y$, Hirai K, Fukazawa Y, Sato H and Ohtaki S (1995) Apoptosis in thyroid tissue from patients with Hashimoto's thyroiditis. Autoimmunity 20: $231-236$

16. Tanimoto C, Hirakawa S, Kawasaki H, Hayakawa N and Ota Z (1995) Apoptosis in thyroid diseases: a histochemical study. Endoc. J. 42: 193-201

17. Ajjan RA, Watson PF and Weetman AP (1996) Cytokines and thyroid function. Adv. Neuroimmunol. 6: 359-386

18. Tang H, Mignon-Godefroy K, Meroni PL, Garotta G, Charreire J and Nicoletti F (1993) The effects of a monoclonal antibody to interferon-gamma on experimental autoimmune thyroiditis (EAT): prevention of disease and decrease of EAT-specific T cells. Eur. J. Immunol. 23: 275-278

19. Kawakami Y, Kuzuya N, Watanabe T, Uchiyama Y and Yamashita K (1990) Induction of experimental thyroiditis in mice by recombinant interferon gamma administration. Acta Endocrinologica 122: 41-48

20. Frohman M, Francfort JW and Cowing C (1991) T-dependent destruction of thyroid isografts exposed to IFN-gamma. J Immunol 146: 2227-2234

21. Alimi E, Huang S, Brazillet MP and Charreire J (1998) Experimental autoimmune thyroiditis (EAT) in mice lacking the IFN-gamma receptor gene. Eur. J. Immunol. 28: $201-208$

22. Stull SJ, Sharp GC, Kyriakos M, Bickel JT and Braley-Mullen H (1992) Induction of granulomatous experimental autoimmune thyroiditis in mice with in vitro activated effector T cells and anti-IFN-gamma antibody. J Immunol 149: 22192226
23. Schuppert F, Hiller W, Weinland G, Hoang-Vu C, von zur Muhlen A and Kohn LD (1996) lodide, cytokines and TSH-receptor expression in Graves' disease. Exp. Clin. Endocrinol. Diabetes 104: 68-74

24. Kawakami A, Eguchi K, Matsuoka N, Tsuboi M, Kawabe Y, Ishikawa N, Ito Kand Nagataki S (1996) Thyroid-stimulating hormone inhibits Fas antigen-mediated apoptosis of human thyrocytes in vitro. Endocrinology 137: 3163-3169

25. Paolieri F, Salmaso C, Battifora M, Montagna P, Pesce G, Bagnasco M, Richiusa P, Galluzzo A and Giordano C (1999) Possible pathogenetic relevance of interleukin-1 beta in 'destructive' organ-specific autoimmune disease (Hashimoto's thyroiditis). Ann. NY. Acad. Sci. 876: 221-228

26. Bretz JD, Rymaszewski M, Arscott PL, Myc A, Ain KB, Thompson NW and Baker, Jr JR (1999) TRAIL death pathway expression and induction in thyroid follicular cells. J. Biol. Chem. 274: 23627-23632

27. Arscott PL, Knapp J, Rymaszewski M, Bartron JL, Bretz JD, Thompson NW and Baker Jr JR (1997) Fas (APO-1, CD95)-mediated apoptosis in thyroid cells is regulated by a labile protein inhibitor. Endocrinology 138: 5019-5027

28. Itoh N, Yonehara S, Ishii A, Yonehara M, Mizushima S, Sameshima M, Hase A Seto Y and NagataS (1991) The polypeptide encoded by the cDNA for human cell surface antigen Fas can mediate apoptosis. Cell 66: 233-243

29. Luttmann W, Opfer A, Dauer E, Foerster M, Matthys H, Eibel H, Schulze-Osthoff K, Kroegel C and Virchow JC (1998) Differential regulation of CD95 (Fas/APO-1) expression in human blood eosinophils. Eur. J. Immunol. 28: 2057-2065

30. Griffith TS, Chin WA, Jackson GC, Lynch DH and Kubin MZ (1998) Intracellular regulation of TRAIL-induced apoptosis in human melanoma cells. J. Immunol. 161: $2833-2840$

31. Griffith TS, Rauch CT, Smolak PJ, Waugh JY, Boiani N, Lynch DH, Smith CA, Goodwin RG and Kubin MZ (1999) Functional analysis of TRAIL receptors using monoclonal antibodies. J. Immunol. 162: 2597-2605

32. Frank S, Kohler U, Schackert G and Schackert HK (1999) Expression of TRAIL and its receptors in human brain tumors. Biochem. Biophys. Res. Commun. 257: $454-459$

33. Kim K, Fisher MJ, Xu SQ and el-Deiry WS (2000) Molecular determinants of response to TRAIL in killing of normal and cancer cells. Clin. Cancer Res. 6:335346

34. Jo M, Kim TH, Seol DW, Esplen JE, Dorko K, Billiar TR and Strom SC (2000) Apoptotis induced in normal human hepatocytes by tumornecrosis factor-related apoptosis-inducing ligand [see comments]. Nature Med. 6: 564-567

35. Leverkus M, Neumann M, Mengling T, Rauch CT, Brocker EB, Krammer PH and Walczak H (2000) Regulation of tumor necrosis factor-related apoptosisinducing ligand sensitivity in primary and transformed human keratinocytes. Cancer Res. 60: 553-559

36. Mitsiades N, Poulaki V, Tseleni-Balafouta S, Koutras DA and Stemenkovic (2000) Thyroid carcinoma cells are resistant to Fas-mediated apoptosis but sensitive tumor necrosis factor-related apoptosis-inducing ligand. Cancer Res. 60: $4122-4129$

37. Wendling U, Walczak H, Dorr J, Jaboci C, Weller M, Krammer PH and Zipp F (2000) Expression of TRAIL receptors in human autoreactive and foreign antigen-specific T cells. Cell Death Differ. 7: 637-644

38. Kothny-Wilkes G, Kulms D, Poppelmann B, Luger TA, Kubin M and Schwarz T (1998) Interleukin-1 protects transformed keratinocytes from tumor necrosis factor-related apoptosis-inducing ligand. J. Biol. Chem. 273: 29247-29253

39. Pan G, NiJ, WeiYF, Yu G, GentzRand DixitVM (1997)Anantagonistdecoy receptor and a death domain-containing receptor for TRAIL. Science 277: 815-818

40. Marsters SA, Sheridan JP, Pitti RM, Huang A, Skubatch M, Baldwin D, Yuan J, Gurney A, Goddard AD, Godowski P and Ashkenazi A (1997) A novel receptor for Apo2L/TRAIL contains a truncated death domain. Curr. Biol. 7: 1003-1006

41. Ashkenazi A and Dixit VM (1999) Apoptosis control by death and decoy receptors. Curr. Opin. Cell. Biol. 11: 255-260

42. Elkon KB (1997) Apoptosis and autoimmunity. Journal of Rheumatology 24:6-7

43. Mountz JD, Wu J, Cheng J and Zhou T (1994) Autoimmune disease. A problem of defective apoptosis. Arthritis Rheum. 37: 1415-1420

44. O'Reilly LA and Strasser A (1999) Apoptosis and autoimmune disease. Inflamm Res. 48: 5-21

45. Wang J, Zheng L, Lobito A, Chan FK, Dale J, Sneller M, Yao X, Puck JM, Straus SE and Lenardo MJ (1999) Inherited human Caspase 10 mutations underlie defective lymphocyte and dendritic cell apoptosis in autoimmune lymphoproliferative syndrome type II. Cell 98: 47-58 
46. Pai SI, Wu GS, Ozoren N, Wu L Jen J, Sidransky D and El-Deiry WS (1998) Rare loss-of-function mutation of a death receptor gene in head and neck cancer Cancer Res. 58: 3513-3518

47. Song K, Chen Y, Goke R, Wilmen A, Seidel C, Goke A, Hilliard B and Chen Y (2000) Tumor Necrosis Factor-related Apoptosis-inducing Ligand (TRAIL) Is an Inhibitor of Autoimmune Inflammation and Cell Cycle Progression. J. Exp. Med. 191: $1095-1103$

48. Hilliard B, Wilmen A, Seidel C, Liu TS, Goke R and Chen Y (1314) Roles of TNFRelated Apoptosis-Inducing Ligand in Experimental Autoimmune Encephalomyelitis. J. Immunol. 166: 1314-1319

49. Bretz JD and Baker Jr JR (2001) Apoptosis and autoimmune thyroid disease: following the TRAIL to thyroid destruction? Clin. Endocrinol. 11: 1-11

50. Bretz JD and Baker Jr JR (2000) Role of Apoptosis in Autoimmune Thyroid Disease. 14 ed. In Harrison's Online, The McGraw-Hill Companies, Inc.) http:// www.harrisonsonline.com

51. Dayan CM, Elsegood KA and Maile R (1997) FasL expression on epithelial cells: the Bottazzo-Feldman hypothesis revisited. Immunol. Today 18: 203
52. Jo M, Kim TH, Seol DW, Esplen JE, Dorko K, Billiar TR and Strom SC (2000) Apoptosis induced in normal human hepatocytes by tumor necrosis factorrelated apoptosis-inducing ligand. Nature Med. 6: 564-567

53. Lawrence D, Shahrokh Z, Marsters S, Achilles K, Shih D, Mounho B, Hillan K, Totpal K, DeForge L, Schow P, Hooley J, Sherwood S, Pai R, Leung S, Khan L, Gliniak B, Bussiere J, Smith CA, Strom SS, Kelley S, Fox JA, Thomas D and Ashkenazi A(2001) Differential hepatocyte toxicity of recombinant Apo2L/TRAIL versions. Nature Med. 7: 383-385

54. Chinnaiyan AM, Prasad U, Shankar S, Hamstra DA, Shanaiah M, Chenevert TL, Ross BD and Rehemtulla A (2000) Combined effect of tumor necrosis factorrelated apoptosis-inducing ligand and ionizing radiation in breast cancer therapy. Proc. Natl. Acad. Sci. USA, 97: 1754-1759

55. Killinger Jr WA, Dorofi DB, Tinsley Jr EA, Keagy A and Johnson Jr G (1992) Flow cytometric analysis of organ preservation-induced endothelial cell membrane damage. Ann. Thorac. Surg. 53: 472-476 